\title{
Thermal and Electrical Properties of Sn-Zn-Bi Ternary Soldering Alloys
}

\author{
M. A. Wadud1, M. A. Gafur'², M. R. Qadir'2, M. O. Rahman'1 \\ ${ }^{1}$ Department of Physics, Jahangirnagar University, Savar, Bangladesh \\ ${ }^{2}$ PP\&PDC, BCSIR, Dhaka, Bangladesh \\ Email: wadud_aleem@yahoo.com, "d_r_magafur@yahoo.com
}

Received 28 August 2015; accepted 17 November 2015; published 20 November 2015

Copyright (C) 2015 by authors and Scientific Research Publishing Inc.

This work is licensed under the Creative Commons Attribution International License (CC BY). http://creativecommons.org/licenses/by/4.0/

(c) (i) Open Access

\begin{abstract}
$\mathrm{Sn}-\mathrm{Zn}$ based solder is a possible replacement of $\mathrm{Pb}$ solder because of its better mechanical properties. The alloys need to be studied and explored to get a usable solder alloy having better properties. In this work, eutectic Sn-9Zn and three Tin-Zinc-Bismuth ternary alloys were prepared and investigated their thermal and electrical properties. Thermo-mechanical Analysis and Differential Thermal Analysis were used to investigate thermal properties. Microstructural study is carried out with Scanning Electron Microscope. The alloys have single melting point. The co-efficient of thermal expansion and co-efficient of thermal contraction varies with alloy composition and temperature range. Electrical conductivity changes with $\mathrm{Bi}$ addition.
\end{abstract}

\section{Keywords}

\section{Lead Free Solder Alloy, Eutectic Alloy, DTA, TMA, Conductivity}

\section{Introduction}

Tin-Lead solders have been widely used in electronic and optoelectronic packaging due to their low cost and low melting temperature and good soldering properties. But lead is an aggressive threat for human health and the environment due to its toxicity. Many countries banned using lead and lead alloys [1] [2] for their use in packaging. Waste Electronic and Electronic Equipment (WEEE) and Restriction of Hazardous Substances (RoHS) approved banning the use of lead in European Union countries effective July 2006. The USA, the EU and Japan forbade the use of Lead containing products [3] [4]. Because of the toxicity of lead, traditional Sn-Pb solders are now being replaced with Sn-base soldering alloys containing additions of other metals ( $\mathrm{Ag}, \mathrm{Bi}$, In, etc.) [5]-[9]. Au-Sn is thought to be alternative but its mechanical properties are not sufficient [10] [11]. SAC

\footnotetext{
${ }^{*}$ Corresponding author.
}

How to cite this paper: Wadud, M.A., Gafur, M.A., Qadir, M.R. and Rahman, M.O. (2015) Thermal and Electrical Properties of Sn-Zn-Bi Ternary Soldering Alloys. Materials Sciences and Applications, 6, 1008-1013. 
solder also an alternative has eutectic point at $217^{\circ} \mathrm{C}$ [12] and good wetting properties [13]. The search for a perfect Lead-free solder alloy with equivalent mechanical and thermal properties to Sn-Pb solder is an urgent task. Targeting the deadline (July 1, 2006), a large number of studies on Lead-free solders were being conducted worldwide to find an appropriate replacement. Nowadays, Sn-Ag base alloys containing one or more additional metal are being used as alternating soldering alloy [5] [6] [8] [14]. Soldering alloy is the prime material for electronic packaging. Melting temperature, mechanical properties, wetting properties, thermal expansion and electrical conductivity, etc. are very important issue for selecting a solder material. Recently Sn-Zn eutectic alloys have received particular attention due to its low melting temperature [15] [16]. Sn-Zn eutectic alloy is considered as a good candidate for the replacement of traditional Pb-containing solder alloy [17]-[19]. However, available information in literature about the evolution and properties of Sn-Zn solder alloy is not enough [20]. In this study eutectic Sn-Zn alloy and three Sn-Zn-Bi ternary alloys containing 1\%, 2\% and 3\% Bi were developed and their thermal and electrical properties were measured. Melting temperature was studied with differential thermal analyzer (DTA). Thermo-mechanical analysis (TMA) was carried to study thermal expansion. Electrical conductivity was measured with Eddy current method.

\section{Experimental Work}

Sn-Zn-Bi solder alloys were prepared by using Tin, Zinc and Bi with 99.9\% purity. Four alloys having different compositions were prepared and studied here. Sn-Zn with desire composition was melted in an electrical furnace in a clay-graphite crucible at $450^{\circ} \mathrm{C}$ temperature for 30 minutes. Then $\mathrm{Bi}$ was added and the mixture again kept in furnace for 20 minutes. Then the liquid alloy poured in a cast iron mould having dimensions $300 \mathrm{~mm} \times 10$ $\mathrm{mm} \times 10 \mathrm{~mm}$ and $10 \mathrm{~mm}$ mould thickness. The as cast alloys were sectioned and polished with emery paper and then wet polished. Polished samples then cleaned and etched by ethanol with $5 \% \mathrm{HNO}_{3}$ to observe microstructure. Prepared samples were investigated by JOEL JSM-7600F scanning electron microscope. The co-efficient of thermal expansion was studied up to $170^{\circ} \mathrm{C}$ with TMA/SS6300, SII Nanotechnology Inc; Japan at a heating rate of $10^{\circ} \mathrm{C} / \mathrm{min}$. Melting behavior was studied with TG/DTA6300 SII nanotechnology, Japan at a heating rate of $20^{\circ} \mathrm{C} / \mathrm{min}$ in a nitrogen environment. In this paper four alloys are referred as $\mathrm{Sn}-9 \mathrm{Zn}, \mathrm{Sn}-8 \mathrm{Zn}-1 \mathrm{Bi}$, $\mathrm{Sn}-7 \mathrm{Zn}-2 \mathrm{Bi}$ and $\mathrm{Sn}-6 \mathrm{Zn}-3 \mathrm{Bi}$. The pouring temperature of the liquid solder alloys and the preheating temperature of the metal mold are $450^{\circ} \mathrm{C}$ and $220^{\circ} \mathrm{C}$, respectively.

\section{Results and Discussion}

\subsection{Differential Thermal Analysis}

Melting temperature is the main characteristic of a solder alloy while it determines the maximum operating temperature of the system and the minimum processing temperature its components must survive [21]. Figure 1 shows the superimposed Differential Thermal Analysis (DTA) curves of Sn-Zn-Bi alloys. Melting temperature, solidification temperature and pasty range of the alloys are presented in Table 1 . They are extracted from the DTA curves. The melting temperature is one of the most important considerations for the development of the solder alloy because the high melting temperature of the solder alloy increases the reflowing temperature in the electronic packaging process and causes thermal damage to the polymer substrate. Melting temperature of Sn-9Zn alloy is $199.4^{\circ} \mathrm{C}$. It is seen that Bi addition decreases the melting temperature of Sn-9Zn alloy. From the SEM microstructure it is seen that Bi rich platelets are observed in Sn-6Zn-3Bi alloy (Figure 2(d)). Bi forms 43Sn-57Bi eutectic composition with the addition of Bi in Sn-9Zn alloy which has a relatively low melting temperature. This eutectic formation contributes in lowering the melting temperature of Sn-9Zn alloy. It is thought that some of high concentration Bi area might have formed 43Sn-57Bi eutectic. Similar criteria have also been reported by other authors [22] [23]. All the alloys show single melting temperature.

\subsection{Thermo-Mechanical Analysis}

Thermo-mechanical Analysis (TMA) data obtained for Sn(9-x)Zn-xBi alloys at different temperature range is shown in Figure 3. It is observed that co-efficient of thermal expansion (CTE) changes with temperature. This is why CTE presented for two temperature range. The coefficient of thermal expansion of Sn-9Zn alloy is $23.39867 \times 10^{-6} /{ }^{\circ} \mathrm{C}$ which is a good agreement with the literature value [24]. At low temperature range CTE of Sn-9Zn alloy increases with Bi addition. At high temperature range nature of CTE is similar with low 


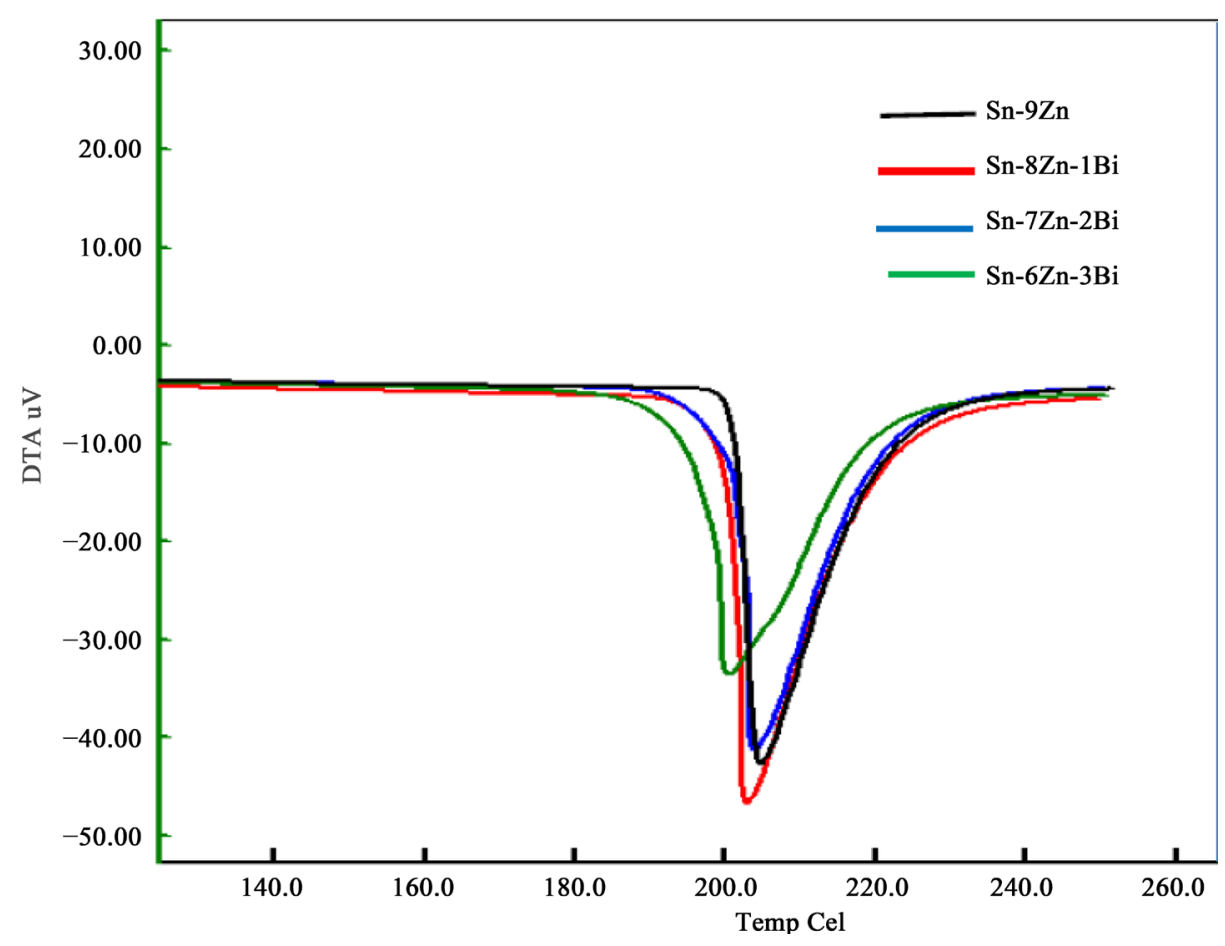

Figure 1. Endothermic peaks of the Sn-(9-x)Zn-xBi alloy.

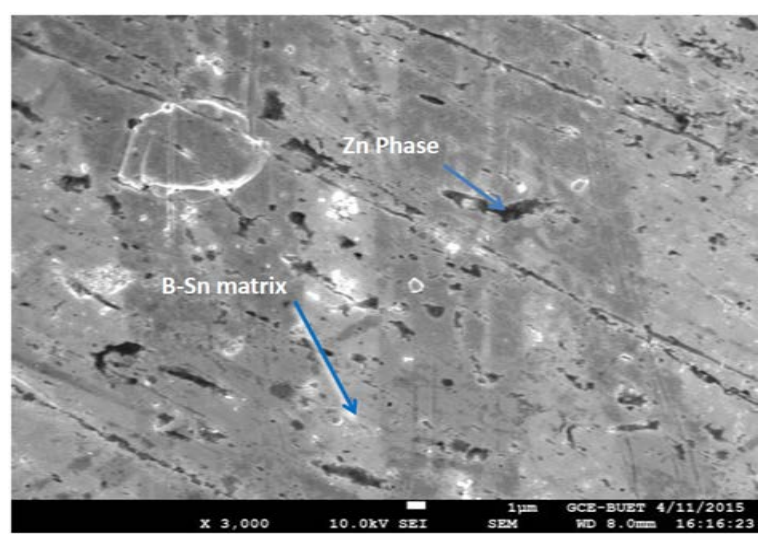

(a)

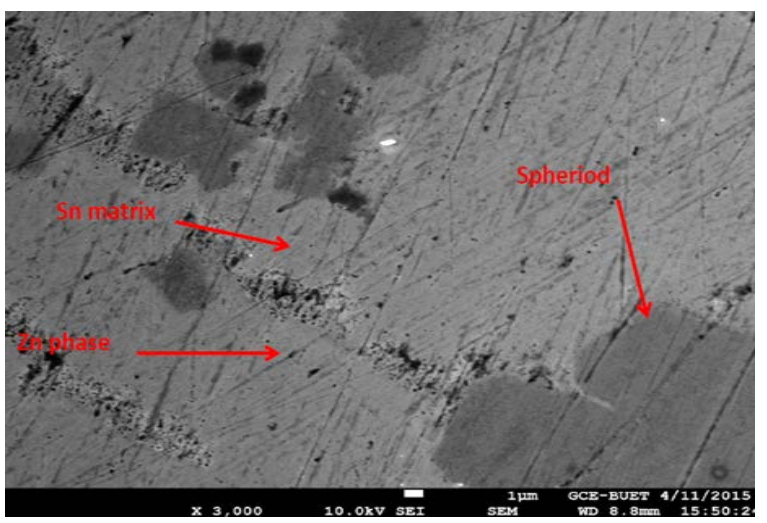

(c)

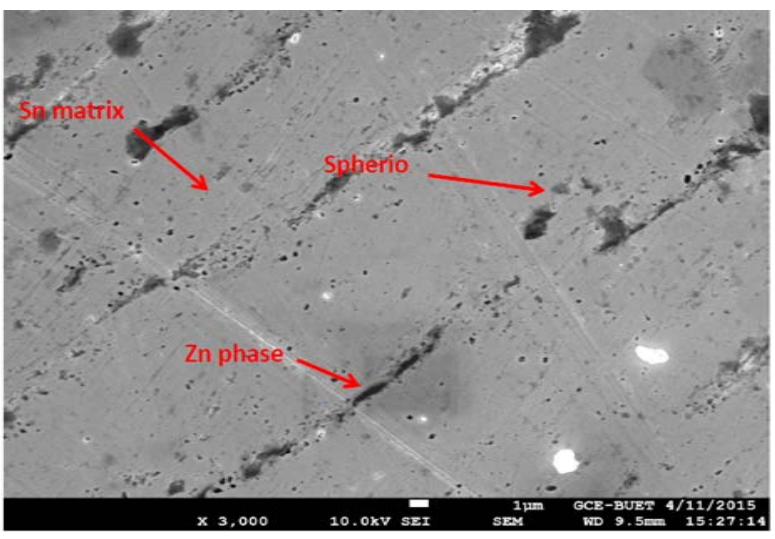

(b)

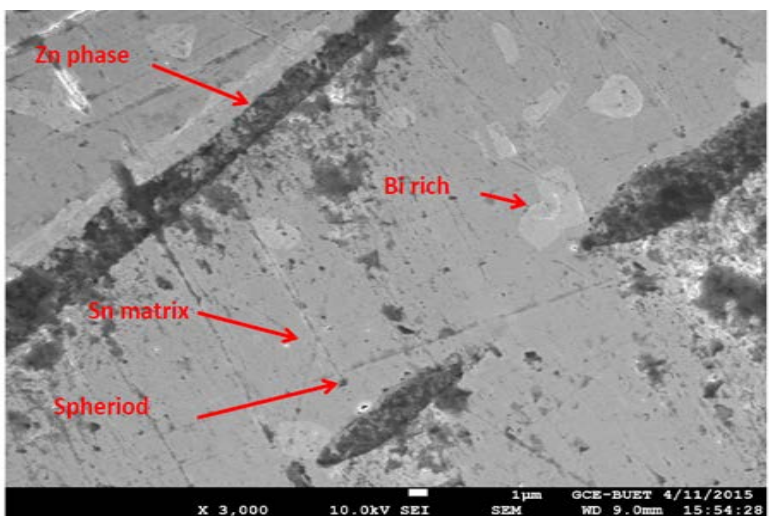

(d)

Figure 2. SEM micrograph of (a) Sn-9Zn alloy, (b) Sn-8Zn-1Bi alloy, (c) Sn-7Zn-2Bi alloy and (d) Sn-6Zn-3Bi alloy. 
Table 1. Liquidus and solidus point.

\begin{tabular}{ccccc}
\hline Alloy & $\begin{array}{c}\text { Solidus Temperature } \\
{ }^{\circ} \mathrm{C}\end{array}$ & $\begin{array}{c}\text { Liquids Temperature } \\
{ }^{\circ} \mathrm{C}\end{array}$ & $\begin{array}{c}\text { Pasty Range } \\
{ }^{\circ} \mathrm{C}\end{array}$ & \multicolumn{2}{c}{$\begin{array}{c}\text { Endothermic Peak } \\
{ }^{\circ} \mathrm{C}\end{array}$} \\
\hline Sn-9Zn & 199.4 & 224 & 24.6 & 204.1 \\
Sn-8Zn-1Bi & 198.1 & 223.5 & 25.4 & 203.1 \\
Sn-7Zn-2Bi & 197.3 & 224.8 & 27.5 & 202.4 \\
Sn-6Zn-3Bi & 196.1 & 225.5 & 29.4 & 203.1 \\
\hline
\end{tabular}

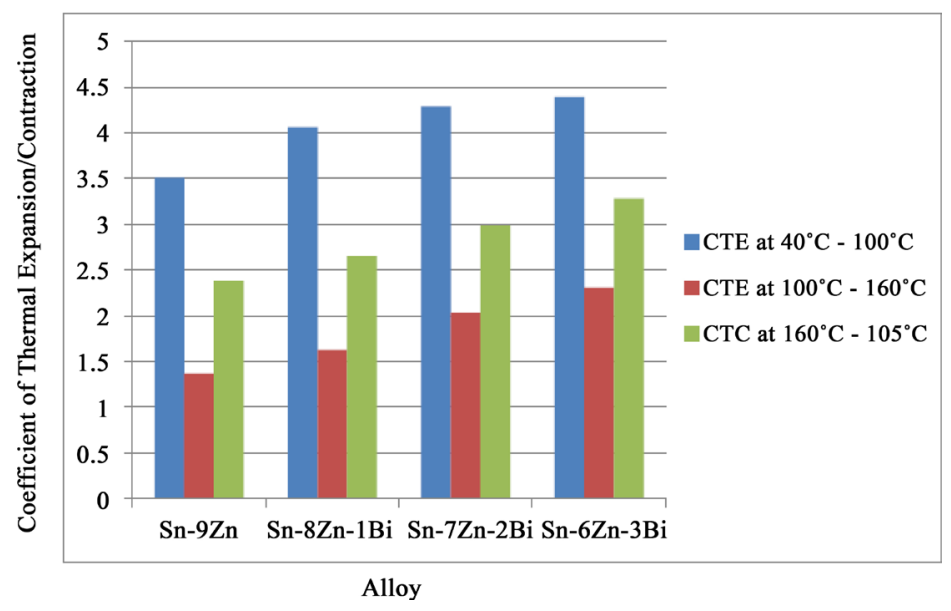

Figure 3. CTC/CTE of Sn-(9-x)Zn-xBi alloy.

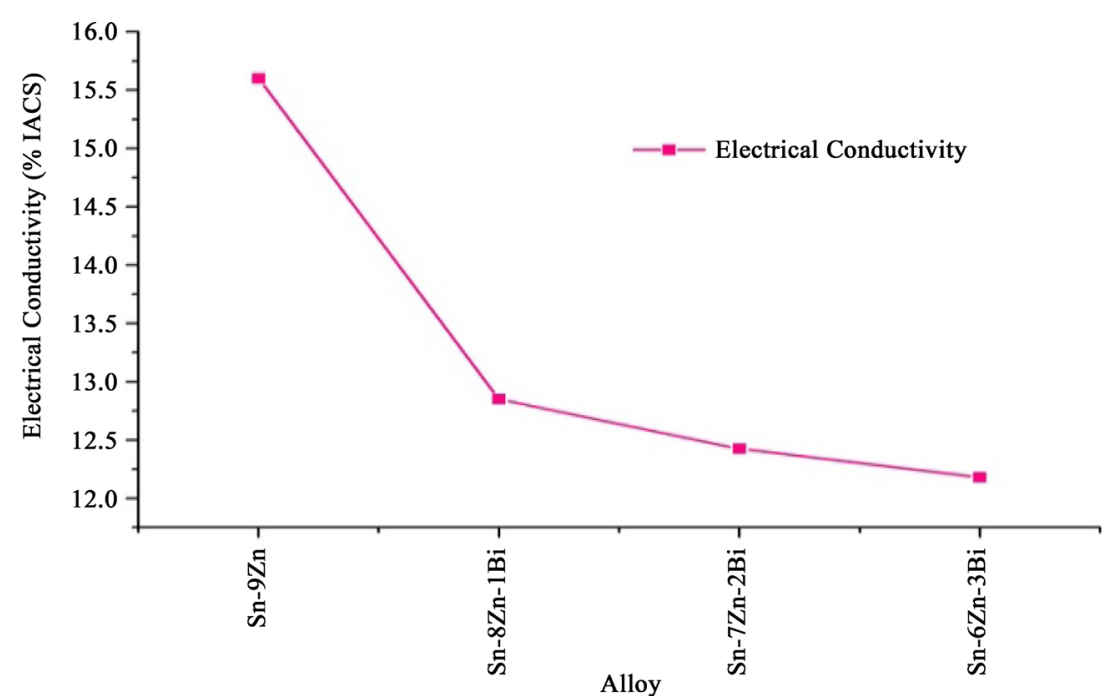

Figure 4. Electrical conductivity of Sn-Zn-Bi alloy.

temperature but the numerical value of CTE is less than that of the low temperature. Co-efficient of thermal contraction (CTC) of Sn-9Zn alloy increases with addition of Bi. Thermal expansion depends on bonding energy which also affects the melting point of the solid. High melting point materials likely to have lower thermal expansion [25]. From DTA it is observed that Bi decreases the melting temperature of Sn-9Zn alloy. Low melting points means low bonding energy which decreases the CTE.

\subsection{Electrical Conductivity of Sn-(9-x)Zn-xBi}

Figure 4 shows the electrical conductivity of Sn-(9-x) Zn-xBi alloy. It shows that the conductivity is continuously decreases with $\mathrm{Bi}$ addition. $\mathrm{Bi}$ is soluble in $\beta$-Sn and up to $3 \mathrm{wt} . \% \mathrm{Bi}$ can remain in solid solution. The 
implication of this would be to expect some contribution to hardening from solid solution [13] [22]. Bi rich platelets are observed in SEM microstructure of Sn-6Zn-3Bi alloy (Figure 2(d)).The continuous decrease of conductivity can be attributed to solid solution of high resistance Bi phase in solder matrix, which acts as scattering centers for conduction electrons in crystals [26]. Similar criteria were reported by other author [27].

\section{Conclusion}

Eutectic Sn-Zn alloy and three Sn-Zn-Bi ternary alloys were cast. Melting behavior, thermal expansion and contraction and electrical conductivity were investigated. Thermal properties of Sn-Zn alloy changes with Bi addition. Melting point decreases with Bi addition. Coefficient of thermal expansion and coefficient of thermal contraction increase with $\mathrm{Bi}$ addition. Electrical conductivity decreases with $\mathrm{Bi}$ addition.

\section{Acknowledgements}

The authors are grateful to Bangladesh Council of Scientific and Industrial Research for providing them with the research facilities to carry out the work.

\section{References}

[1] Mc Cormack, M., Jin, S. and Chen, H.S. (1994) New Lead-Free, Sn-Zn-In Solder Alloys. The Journal of Electronic Materials, 23, 687. http://dx.doi.org/10.1007/BF02653357

[2] Suganuma, K. (2001) Advances in Lead-Free Electronics Soldering. Current Opinion in Solid State \& Materials Science, 555-564. http://dx.doi.org/10.1016/S1359-0286(00)00036-X

[3] Matsugi, K., Iwashta, Y., Choi, Y.-B., Sasaki, G. and Fuji, K. (2011) Long Time Stability of Pb-Free Sn-9Zn Elements for Ac-Low Voltage Fuse Performance. Materials Transaction, 52, 753. http://dx.doi.org/10.2320/matertrans.M2010389

[4] US Environmental Protection Agency (1991) Comprehensive Review of Lead in the Environment under TSC, 56FR22096-98.

[5] Alam, M.O., Chan, Y.C. and Tu, K.N. (2003) Lead-Free Solders: Materials Reliability for Electronics. Journal of Applied Physics, 94, 4108. http://dx.doi.org/10.1063/1.1602563

[6] Chiu, M.Y., Wang, S.S. and Chuang, T.H. (2002) Intermatallic Compounds Formed during Interfacial Reactions between Liquid Sn-8Zn-3Bi Solders and Ni Substrates. Journal of Electronic Materials, 311, 494-499. http://dx.doi.org/10.1007/s11664-002-0105-8

[7] Yoon, J.-W., Kim, S.-W., Koo, J.-M., Kim, D.-G. and Jung, S.-B. (2004) Reliability Investigation and Interfacial Reaction of Ball-Grid-Array Packages Using the Lead-Free Sn-Cu Solder. Journal of Electronic Materials, 33, 1190. http://dx.doi.org/10.1007/s11664-004-0122-x

[8] Lee, H.-T., Lin, H.-S., Lee, C.-S. and Chen, P.-W. (2005) Reliability of Sn-Ag-Sb Lead-Free Solder Joints. Materials Science and Engineering: A, 407, 36-44. http://dx.doi.org/10.1016/j.msea.2005.07.049

[9] Rizvi, M.J., Chan, Y.C., Bailey, C., Lu, H. and Islam, M.N. (2006) Effect of Adding 1 wt\% Bi into the Sn-2.8Ag0.5Cu Solder Alloy on the Intermetallic Formations with Cu-Substrate during Soldering and Isothermal Aging. Journal of Alloys and Compounds, 407, 208. http://dx.doi.org/10.1016/j.jallcom.2005.06.050

[10] Debski, A., Gasior, W., Moser, Z. and Major, R. (2010) Enthalpy of Formation of Intermetallic Phases from the Au-Sn System. Journal of Alloys and Compounds, 491, 173-177. http://dx.doi.org/10.1016/j.jallcom.2009.11.003

[11] Chung, H.M., Chen, C.M., Lin, C.P. and Chen, C.J. (2009) Microstructural Evolution of the Au-20 wt.\% Sn Solder on the Cu Substrate during Reflow. Journal of Alloys and Compounds, 485, 219-224. http://dx.doi.org/10.1016/j.jallcom.2009.06.018

[12] Zeng, G., McDonald, S. and Nogita, K. (2012) Stuart McDonald, Kazuhiro Nogita. Microelectronics Reliability, 52, 1306-1322. http://dx.doi.org/10.1016/j.microrel.2012.02.018

[13] Matahir, M., Chin, L.T., Tan, K.S. and OOlofinjana, A. (2011) Mechanical Strength and Its Variability in Bi-Modified Sn-Ag-Cu Solder Alloy. Journal of Achievements in Material and Manufacturing Engineering, 46, 50-56.

[14] Cheng, Y.-T., Chan, Y.-T. and Chen, C.-C. (2010) Wettability and Interfacial Reactions between the Molten Sn-3.0 wt.\%Ag-0.5 wt.\%Cu Solder(SAC)and Ni-Co Alloys. Journal of Alloys and Compounds, 507, 419-424. http://dx.doi.org/10.1016/j.jallcom.2010.08.006

[15] Cheng, S.-C. and Lin, K.-L. (2005) Microstrucure and Mechanical Properties of Sn-8.55Zn-1Ag-XAl Solder Alloys. Materials Transactions, 46, 42-47. http://dx.doi.org/10.2320/matertrans.46.42 
[16] Azizan, F.M., Purwanto, H. and Mustafa, M.Y. (2012) Effect of Adding Ag on Tensile and Microstructure Properties of Zinc Alloy. International Journal of Engineering \& Technology, 12, 78-84.

[17] Suganuma, K. and Kim, K.S. (2007) Sn-Zn Low Temperature Solder. Journal of Materials Science-Materials in Electronics, 18, 121-127. http://dx.doi.org/10.1007/s10854-006-9018-2

[18] Wang, H., Xue, S.B., Han, Z.J. and Wan, J.X. (2007) Research Status and Prospect of Sn-Zn Based Lead-Free Solders. Welding and Joining, 2, 31-35.

[19] El Daly, A.A. and Hammad, A.E. (2010) Elastic Properties and Thermal Behavior of Sn-Zn Based Lead-Free Solder Alloys, 505, 793-800.

[20] Zhao, G.J., Sheng, G.M., Wu, L.L. and Yuan, Z.J. (2012) Interfacial Characteristics and Microstructural Evolution of Sn-6.5Zn Solder/Cu Substrate Joints during Aging. Transactions of Nonferrous Metals Society of China, 22, 19541960. http://dx.doi.org/10.1016/S1003-6326(11)61413-1

[21] Glazer, J. (1994) Microstructure and Mechanical Properties of Pb-Free Solder Alloys for Low-Cost Electronic Assembly: A Review. Journal of Electronic Materials, 23, 693-700. http://dx.doi.org/10.1007/bf02651361

[22] El-Daly, A.A., Swilem, Y., Makled, M.H., El-Shaarawy, M.G. and Abdraboh, A.M. (2009) Thermal and Mechanical Properties of Sn-Zn-Bi Lead-Free Solder Alloys. Journal of Alloys and Compounds, 484, 134-142. http://dx.doi.org/10.1016/j.jallcom.2009.04.108

[23] Fries, S.G., Lukas, H.L., Kuang, S. and Effenberg, G. (1991) Calculation of the Al-Zn-Sn Ternary System. The Institute of Metals, London, 280-286.

[24] Matsugi, K., Sasaki, G., Yanagisawa, O., Kumagai, Y. and Fujii, K. (2007) Electrical and Thermal Characteristics of Pb-Free Sn-Zn Alloys for an AC-Low Voltage Fuse Element. Materials Transactions, 48, 1105-1112. http://dx.doi.org/10.2320/matertrans.48.1105

[25] https://en.wikipedia.org/wiki/thermal_expansion

[26] Kasap, S.O. (2002) Principles of Electronic Materials and Devices. Second Edition, McGraw-Hill, New York. http://Materials.Usask.Ca

[27] Gouda, E.S. and Aziz, H.A. (2012) Effect of Bi Additions on Structure and Properties of Sn-9Zn-1Ag Lead-Free Solder Alloys. Journal of Materials Science and Engineering B, 2, 6381-6388. 